\title{
MRI-Based Assessment of the Pharyngeal Constrictor Muscle as a Predictor of Surgical Margin after Transoral Robotic Surgery in HPV-Positive Tonsillar Cancer
}

\author{
(D)Y.J. Kim, (DW.-J. Jeong, (D) Y.J. Bae, (D) H. Kim, (D)B.S. Choi, (D).H. Jung, (D).H. Baik, (D). Sunwoo, and (D).H. Kim
}

\begin{abstract}
BACKGROUND AND PURPOSE: Transoral robotic surgery is an emerging strategy for treating human papillomavirus-positive cancers, but the role of MR imaging in predicting the surgical outcome has not been established. We aimed to identify preoperative MR imaging characteristics that predispose the outcome of transoral robotic surgery toward an insecure (positive or close) surgical margin in human papillomavirus-positive tonsillar squamous cell carcinoma.
\end{abstract}

MATERIALS AND METHODS: Between December 2012 and May 2019, sixty-nine patients underwent transoral robotic surgery at our institution. Among these, 29 who were diagnosed with human papillomavirus-positive tonsillar squamous cell carcinoma, did not receive neoadjuvant treatment, underwent preoperative $3 T$ MR imaging, and had postoperative pathologic reports and were included in this retrospective study. Two neuroradiologists evaluated the preoperative MR imaging scans to determine the tumor spread through the pharyngeal constrictor muscle using a 5-point scale: 1, normal constrictor; 2, bulging constrictor; 3, thinning constrictor; 4, obscured constrictor; and 5, tumor protrusion into the parapharyngeal fat. The risk of an insecure surgical margin (involved or $<1 \mathrm{~mm}$ ) according to the MR imaging scores was predicted using logistic regression with the Firth correction.

RESULTS: The interobserver agreement for the MR imaging scores was excellent $(\kappa=0.955, P<.001)$. A score of $\geq 4$ could predict an insecure margin with $87.5 \%$ sensitivity and $92.3 \%$ specificity (area under the curve $=0.899$ ) and was the only significant factor associated with an insecure margin in the multivariable analysis (OR, 6.59; 95\% Cl, 3.11-22.28; $P<.001)$.

CONCLUSIONS: The pre-transoral robotic surgery MR imaging scoring system for the pharyngeal constrictor muscle is a promising predictor of the surgical margin in human papillomavirus-positive tonsillar squamous cell carcinoma.

ABBREVIATIONS: $\mathrm{AUC}=$ area under the curve; $\mathrm{CN}=$ clinical node; $\mathrm{CT}=$ clinical tumor; $\mathrm{HPV}=$ human papillomavirus; $\mathrm{pN}=$ pathologic node; $\mathrm{PT}=$ pathologic tumor; ROC = receiver operating characteristic; $\mathrm{SCC}=$ squamous cell carcinoma; TORS $=$ transoral robotic surgery

O ropharyngeal squamous cell carcinoma (SCC) is a head and neck cancer with increasing prevalence as a consequence of rising human papillomavirus (HPV) infections. ${ }^{1,2}$ HPV-positive oropharyngeal SCC is known for its excellent prognosis with substantially improved survival compared with HPV-negative SCC. ${ }^{3-5}$ Surgery, radiation, and chemotherapy are the main treatment methods for oropharyngeal SCC and can be used alone or in combination depending on the cancer stage. ${ }^{6}$

Received January 28, 2020; accepted after revision July 29

From the Departments of Radiology (Y.J.K., Y.J.B., B.S.C., S.H.B., L.S., J.H.K.), Otolaryngology-Head and Neck Surgery (W.-J.J., Y.H.J.), and Pathology (H.K.), Seoul National University Bundang Hospital, Seongnam, Republic of Korea.

Yong Ju Kim and Woo-Jin Jeong contributed equally to this article.

This work was supported by the National Research Foundation of Korea grant funded by the Korea government (No. 2019R1F1A1063771) and grant No. 09-2019003 from the Seoul National University Bundang Hospital Research Fund.

Paper previously presented at: American Society of Head and Neck Radiology 53rd Annual Meeting, where it won the first-place scientific exhibit award, October 2-6, 2019; Phoenix, Arizona.
The treatment protocol for HPV-positive SCC has shifted toward a "deintensification" approach to maintain favorable oncologic outcomes while minimizing treatment-related morbidity. ${ }^{7-9}$ Long-term adverse effects from radiation or chemotherapy and high morbidity from traditional surgery through external mandibulotomy can reduce the quality of life, particularly in young patients who have to live with the consequences for far longer. ${ }^{10-13}$ Recently, transoral robotic surgery (TORS) has emerged as a firstline treatment, particularly for early-stage HPV-positive oropharyngeal SCC. ${ }^{14,15}$ While avoiding functional deficits from the traditional external approaches, TORS can reduce the need for adjuvant

Please address correspondence to Yun Jung Bae, MD, PhD, Department of Radiology, Seoul National University Bundang Hospital, 82, Gumi-ro 173beon-gil, Bundang-gu, Seongnam, 13620, Republic of Korea; e-mail: bae729@gmail.com

\footnotetext{
- Indicates open access to non-subscribers at www.ajnr.org

= Indicates article with supplemental on-line appendix and tables.

Indicates article with supplemental on-line photo.

http://dx.doi.org/10.3174/ajnr.A6806
} 
therapy after surgery or can use surgery as a single-technique therapy while preserving oncologic outcomes, particularly when the negative margin is achieved by TORS. ${ }^{2,3,5,16-18}$

Despite these advantages, there is still a risk of obtaining an insecure surgical margin (ie, positive margin involvement by the tumor or a close margin of $<1 \mathrm{~mm}$ between the tumor and the margin) in TORS, which necessitates adjuvant therapies, even in early T1 and T2 tumors. ${ }^{3,19}$ Because oncologic outcomes in such cases are similar to those with chemoradiation alone, ${ }^{3}$ it is important to preselect patients who are expected to have an insecure surgical margin to avoid unnecessary dual treatment. However, no published study has evaluated the preoperative MR imaging characteristics that can predict the surgical margin after TORS. It has been noted that tumor invasion through the pharyngeal constrictor muscle confirmed in a surgical field will likely have a positive margin related to locoregional recurrence, but data supporting an imaging-based predictor are still lacking. ${ }^{2,5,20}$

In our study, we aimed to identify preoperative MR imaging characteristics, particularly with regard to pharyngeal constrictor muscle involvement by the tumor in early stage cancers, that predispose the outcome of TORS toward an insecure surgical margin in HPV-positive tonsillar SCC.

\section{MATERIALS AND METHODS \\ Study Subjects}

This retrospective study was approved by our institutional review board (B-1906-544-101), and the requirement for written informed consent was waived. Between December 2012 and May 2019 at our institution, a nationwide third-referral hospital, we included 36 subjects who met the following criteria: 1) diagnosed with HPVpositive tonsillar SCC, 2) had preoperative 3T MR imaging available, and 3) had postoperative pathologic reports available. Among them, 6 who received neoadjuvant therapy and 1 who did not have a postoperative pathologic report available were excluded from the analysis.

Clinical records were examined for demographic characteristics and staging, and treatment data were obtained from electronic medical records. The clinical primary tumor $(\mathrm{cT})$ and nodal $(\mathrm{cN})$ categories were staged according to the 8th edition of the American Joint Committee on Cancer (AJCC) Cancer Staging Manual..$^{21}$ All included subjects underwent TORS using the da Vinci surgical robotic system (Intuitive Surgical) performed by 2 head and neck surgeons (W-J.J. and Y.H.J. with 10 and 15 years' experience in head and neck surgery, respectively). Adjuvant treatment was considered when the cancer-free margin was insufficient. Follow-up surveillance was initially performed 3 months after the operation and every 3-6 months after the initial follow-up using CT or MR imaging and/or PET/CT to assess locoregional recurrence. The treatment option for each patient was decided at a weekly multidisciplinary tumor board including otorhinolaryngology-head and neck surgeons, oncologists, radiologists, and pathologists, following the 2018 National Comprehensive Cancer Network (NCCN) Clinical Practice Guidelines in Oncology for oropharyngeal cancer. ${ }^{22}$

\section{Image Acquisition}

MR images were acquired using a 3T MR imaging unit (Ingenia; Philips Healthcare) with a 32-channel sensitivity encoding head coil. Axial TSE T2WI was performed with and without fat suppression using the multipoint Dixon technique. The imaging parameters were as follows: TR, $3300 \mathrm{~ms}$; TE, $80 \mathrm{~ms}$; FOV , $180 \times 220 \mathrm{~mm}^{2}$; acquisition matrix, $440 \times 440$; section thickness, $3 \mathrm{~mm}$; no section gap; NEX, 1 . Other parameters for the full MR imaging sequences are described in the On-line Appendix.

\section{Image Analysis}

The cT category according to the 8th edition of the AJCC Cancer Staging Manual for the primary tumor was verified by 1 boardcertified neuroradiologist (Y.J.B. with 10 years' experience in neurology and head and neck imaging) on the basis of MR imaging.

On axial T2WI, tumor spread through the pharyngeal constrictor muscle was independently determined by 2 board-certified neuroradiologists (Y.J.B. and B.S.C. with 20 years' experience in neurology and head and neck imaging) who were blinded to the clinical and histopathologic information. The following 5point scale scoring system was used for the assessment of the status of the pharyngeal constrictor muscle: 1 , normal constrictor; 2 , bulging constrictor; 3 , thinning constrictor; 4 , obscured constrictor; 5, tumor protrusion into the parapharyngeal fat (Fig 1). After an independent reading, the final MR imaging score was designated by 2 readers in consensus and used for further analysis.

\section{Histopathologic Review}

According to the 8th edition of the AJCC Cancer Staging Manual, ${ }^{21}$ the pathologic tumor (pT) and the nodal (pN) statuses were staged by 1 pathologist (H.K.) who specialized in head and neck pathology with 11 years' experience. First, in pathologic specimens, the histologic pharyngeal constrictor muscle invasion by the tumor was evaluated and determined as negative or positive. Next, the status of the surgical margin was determined using the excised superior constrictor muscle as the deep margin. If the surgical margin involved the tumor, it was defined as a positive margin. A close margin was defined as a distance between the surgical margin and the tumor of $<1 \mathrm{~mm}$. Positive and close margins were designated as insecure surgical margins. A negative margin was defined as a distance between the surgical margin and the tumor of $\geq 1 \mathrm{~mm}$.

\section{Statistical Analysis}

Continuous variables are expressed as the median and range. Clinico-histopathologic findings according to the final surgical margin status were compared using the Fisher exact test and the Mann-Whitney $U$ test. Interobserver agreement of MR imaging scores between the 2 readers was tested by Cohen $\kappa$ coefficient statistics: $>0.75$, excellent agreement; $0.40-0.75$, fair-to-good agreement; and $<0.40$, poor agreement. ${ }^{23}$ The relationship between the MR imaging score and the histologic pharyngeal constrictor muscle invasion by the tumor was tested using the Linear-By-Linear Association test and the Spearman correlation. Diagnostic performances predicting an insecure surgical margin using MR imaging scores were evaluated using receiver operating characteristic (ROC) curve analysis. Area under the curve (AUC) values from each ROC curve analysis were compared using the DeLong test. ${ }^{24} \mathrm{We}$ further used the univariable and multivariable 

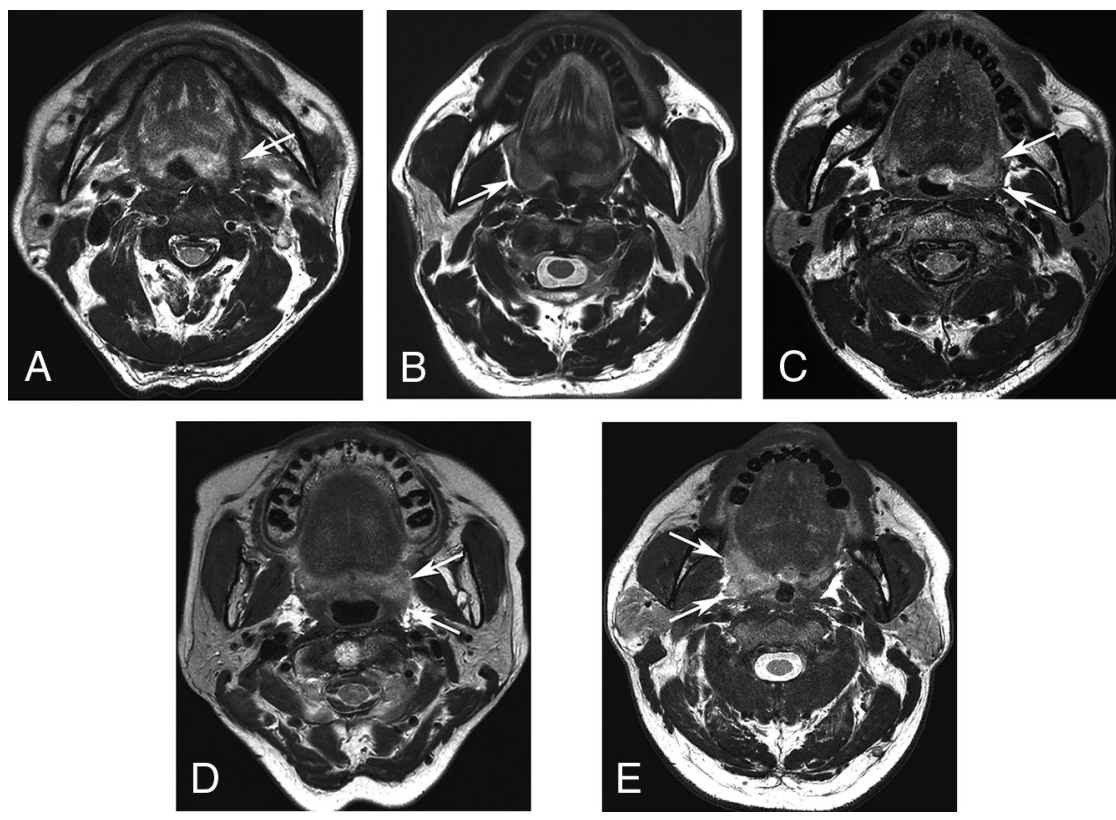

FIG 1. Representative 5-point scale preoperative MR imaging scores for tumor spread through the pharyngeal constrictor muscle. A, Axial T2WI of a 79-year-old man with left-tonsillar SCC revealing a normal constrictor muscle (arrow) (score 1). B, Axial T2WI of a 59-year-old man with right-tonsillar SCC revealing the bulging contour of the constrictor muscle due to the tumor, but normal thickness (arrow) (score 2). C, Axial T2WI of a 66-year-old man with left-tonsillar SCC reveals thinning of the constrictor muscle due to the tumor (score 3). Note that the thickness of the left constrictor muscle is reduced compared with the right side (arrows). D, Axial T2WI of a 69-year-old man with left tonsillar SCC revealing the obscured margin of the constrictor muscle by the tumor (score 4). Note that the normal contour of the constrictor muscle is not visualized (arrows). E, Axial T2WI of a 54-year-old man with right-tonsillar SCC revealing definite protrusion of the tumor into the parapharyngeal fat (arrows) (score 5).

logistic regression with a Firth correction ${ }^{25}$ for risk evaluation of MR imaging scores for the pharyngeal constrictor muscle status to predict an insecure surgical margin after TORS. $P$ values $<.05$ were considered statistically significant. Statistical analyses were performed using SPSS software (Version 17.0; IBM), MedCalc 17.9 (MedCalc Software), and SAS (Version 9.3; SAS Institute).

\section{RESULTS}

\section{Clinico-Histopathologic Findings According to the Surgical Margin}

According to the inclusion and exclusion criteria, 29 patients (26 men, 3 women; age range, $38-80$ years; mean age, 61.6 years) were included for further analysis. Baseline patient characteristics are presented in Table 1 . The cT categories were primarily T2 $(n=23)$, followed by T1 $(n=5)$, and T4 $(n=1)$. Twenty-seven patients underwent TORS with nodal dissection, and 2 patients underwent TORS alone without nodal dissection. The histopathologic results revealed a positive surgical margin in 7 patients, including 1 patient with cT4 who did not undergo neoadjuvant therapy, and a close surgical margin in 9 patients, for a total of 16 patients with an insecure surgical margin. After TORS, 18 patients underwent adjuvant chemoradiation $(n=10)$ or radiation only $(n=8)$, including 11 patients with an insecure surgical margin. Thirteen patients, including 8 with an insecure surgical margin, had lymphovascular invasion, and 2 patients with an insecure surgical margin had perineural invasion in the surgical specimen. There were no differences in the clinico-histopathologic findings according to the surgical margin status (Table 1). On-line Table 1 summarizes the patient information regarding the tumor stage, MR imaging and pathologic findings, and adjuvant therapy.

\section{Interobserver Agreement of MR Imaging Scores for Pharyngeal Constrictor Muscle Involvement}

The interobserver agreement between the 2 readers was excellent $(\kappa=0.955$; $P<.001$ ). The final MR imaging scores were 1 in 5 patients, 2 in 4 patients, 3 in 5 patients, 4 in 9 patients, and 5 in 6 patients.

\section{Correlation between the Preoperative MR Imaging Score and Histologic Pharyngeal Constrictor Muscle Invasion}

There was a significant difference in the state of histologic pharyngeal constrictor muscle invasion by the tumor according to the MR imaging scores (On-line Table 2). Patients with higher MR imaging scores showed a trend toward a positive histologic pharyngeal constrictor muscle invasion by the tumor (Spearman correlation coefficient, $0.601 ; P=.001$ ).

\section{Prediction of the Surgical Margin Using the Preoperative MR Imaging Scores}

In the ROC analysis, $\mathrm{MR}$ imaging scores of $\geq 4$ ( $\mathrm{AUC}=0.899$; 95\% CI, 0.730-0.979) and $\geq 3$ (AUC = 0.846; 95\% CI, 0.664-0.952) enabled good prediction of an insecure surgical margin (Fig 2). However, there was no difference in the diagnostic performance between the 2 thresholds $(P=.477)$. Optimal cutoff scores with AUCs, sensitivities, and specificities are provided in Table 2.

The results of the univariable analysis of the clinico-histopathologic factors and the MR imaging scores affecting the surgical margin status are presented in Table 3. The MR imaging scores were the most significant predictive factors of an insecure margin $(P<.05)$. In the multivariable analysis of the variables with $P$ values $<.15$ in the univariable analysis (ie, $\mathrm{cT}$, pT, and MR imaging score), an MR imaging score of $\geq 4$ was the only significant predictive factor of an insecure surgical margin (Table 4).

\section{Patient Follow-Up}

The mean follow-up period from the time of surgery was $28.9 \pm$ 19.4 months. During the follow-up period, 4 patients with a close surgical margin after TORS exhibited locoregional recurrence on surveillance imaging, and 2 patients were confirmed to have locoregional recurrence using biopsy (On-line Figure). Among 


\begin{tabular}{|c|c|c|c|}
\hline & $\begin{array}{l}\text { Insecure Margin } \\
\quad(n=16)\end{array}$ & $\begin{array}{l}\text { Negative Margin } \\
\qquad(n=13)\end{array}$ & $\begin{array}{c}P \\
\text { Value }\end{array}$ \\
\hline Age (median, range) (yr) & $63,45-80$ & $60,38-78$ & .345 \\
\hline Sex (female:male) & $0: 16$ & $3: 10$ & .078 \\
\hline cT category (No., \%) & & & .164 \\
\hline $\mathrm{cTl}$ & $1,6.3 \%$ & $4,30.8 \%$ & \\
\hline cT2 & $14,87.5 \%$ & $9,69.2 \%$ & \\
\hline cT3 & $0,0 \%$ & $0,0 \%$ & \\
\hline cT4 & $1,6.3 \%$ & $0,0 \%$ & \\
\hline cN category (No., \%) & & & .422 \\
\hline cNO & $1,6.3 \%$ & $2,15.4 \%$ & \\
\hline $\mathrm{cN} 1$ & $15,93.8 \%$ & $11,84.6 \%$ & \\
\hline pT category (No., \%) & & & .202 \\
\hline $\mathrm{pTT}$ & $2,12.5 \%$ & $5,38.5 \%$ & \\
\hline pT2 & $13,81.3 \%$ & $8,61.5 \%$ & \\
\hline PT3 & $0,0 \%$ & $0,0 \%$ & \\
\hline pT4 & $1,6.3 \%$ & $0,0 \%$ & \\
\hline pN category (No., \%) & & & .625 \\
\hline $\mathrm{pNx}$ & $1,6.3 \%$ & $1,7.7 \%$ & \\
\hline pNO & $1,6.3 \%$ & $1,6.3 \%$ & \\
\hline $\mathrm{pN} 1$ & $12,75.0 \%$ & $10,76.9 \%$ & \\
\hline $\mathrm{pN} 2$ & $2,12.5 \%$ & $1,7.7 \%$ & \\
\hline $\begin{array}{l}\text { Histopathologic differentiation } \\
\text { (No., \%) }\end{array}$ & & & .310 \\
\hline Well & $2,12.5 \%$ & $0,0 \%$ & \\
\hline Moderate & $5,31.3 \%$ & $8,61.5 \%$ & \\
\hline Poor & $4,25.0 \%$ & $2,15.4 \%$ & \\
\hline Not applicable ${ }^{a}$ & $5,31.3 \%$ & $3,23.1 \%$ & \\
\hline Positive LVI (No., \%) & $8,50.0 \%$ & $5,38.5 \%$ & .705 \\
\hline $\begin{array}{l}\text { Positive perineural invasion } \\
\text { (No., \%) }\end{array}$ & $2,12.5 \%$ & $0,0 \%$ & .359 \\
\hline Treatment technique (No., \%) & & & .485 \\
\hline TORS alone & $5,31.3 \%$ & $6,46.2 \%$ & \\
\hline TORS + adjuvant radiation & $4,25.0 \%$ & $4,30.8 \%$ & \\
\hline TORS + adjuvant chemoradiation & $7,43.8 \%$ & $3,23.1 \%$ & \\
\hline
\end{tabular}

Note-LVI indicates lymphovascular invasion.

${ }^{a}$ No pathologic statement of the histopathologic differentiation.

on a surgical field is known to increase a risk of locoregional recurrence, ${ }^{26}$ and tumor invasion of the parapharyngeal fat is likely to leave an insecure surgical margin. ${ }^{5}$ These structures can be directly visualized on MR imaging, which is an excellent imaging tool for the head and neck with superb softtissue contrast and high spatial resolution. In this regard, we hypothesized that preoperative MR imaging could predict the surgical margin status by scoring the degree of constrictor and parapharyngeal space invasion by the initial tumor. This hypothesis was supported by our results, which indicated that the 5-scale MR imaging scoring system could effectively predict insecure surgical margins after TORS.

Our results identified 14 patients who were diagnosed with early cT2 or cT1 cancers but had MR imaging scores of $\geq 4$ (On-line Table 1). These 14 patients underwent TORS as a first-line surgical treatment, but 9 had insecure surgical margins necessitating adjuvant therapy according to the NCCN guidelines. On the basis of this observation, it can be inferred that if we can predict insecure margins before TORS, particularly in patients with early-stage cancer (ie, cT1 or cT2), we can preselect the patients who can receive radiation or chemoradiation instead of surgery as a

them, the preoperative MR imaging score was 5 for 2 patients, 4 for 1 patient, and 3 for 1 patient. The other clinico-histopathologic findings of these patients are summarized in On-line Table 3.

\section{DISCUSSION}

In this study, we adopted the MR imaging-based scoring system for assessing the involvement of the pharyngeal constrictor muscle in HPV-positive tonsillar SCC and evaluated the predictive value of the MR imaging score for the surgical margin status after TORS. Patients with higher MR imaging scores showed a trend toward positive histologic pharyngeal constrictor muscle invasion by the tumor. An MR imaging score of $\geq 4$ (obscured pharyngeal constrictor muscle by the tumor or parapharyngeal tumor extension) was the single most significant predictive factor of an insecure surgical margin after TORS with an OR of 6.59. Patients with a higher MR imaging score tended to exhibit locoregional recurrence during follow-up, despite the low preoperative cT category of the tumor.

Assessing the anatomic landmarks of the superior pharyngeal constrictor muscle and the parapharyngeal fat is important in the preoperative evaluation of HPV-positive tonsillar SCC before TORS. Tonsillar SCC invading the pharyngeal constrictor muscle first-line treatment, despite the low clinical T-stage. Therefore, the preoperative MR imaging scoring system may have a significant clinical impact on treatment selection for patients with HPV-positive tonsillar SCC by predicting the surgical margin.

Our study results have important implications for patients who are candidates for TORS. First, MR imaging scores of 4 and 5 not only were related to the histologic pharyngeal muscle invasion by the tumor but also indicated a high probability of obtaining a positive or close margin. It is known that the invasion of the superior constrictor muscle itself should not lead to a positive margin if the surgery is performed correctly and the muscle is excised as the deep margin. However, our findings suggest that tonsillar SCC seemingly invading the constrictor muscle on MR imaging may include microscopic parapharyngeal fat invasion, and the preoperative work-up cannot guarantee tumor-free parapharyngeal fat.

Second, the selection of candidates for TORS as a first-line treatment has predominantly been based on clinical T-staging to date. ${ }^{25,27-30}$ However, because the status of the constrictor muscle or parapharyngeal fat in HPV-positive tonsillar SCC is not currently applied in the AJCC staging ${ }^{21}$ or NCCN guidelines, ${ }^{22}$ there is risk of selecting improper patients for surgery who are predicted to have an insecure margin. We hope that our study result can be a 


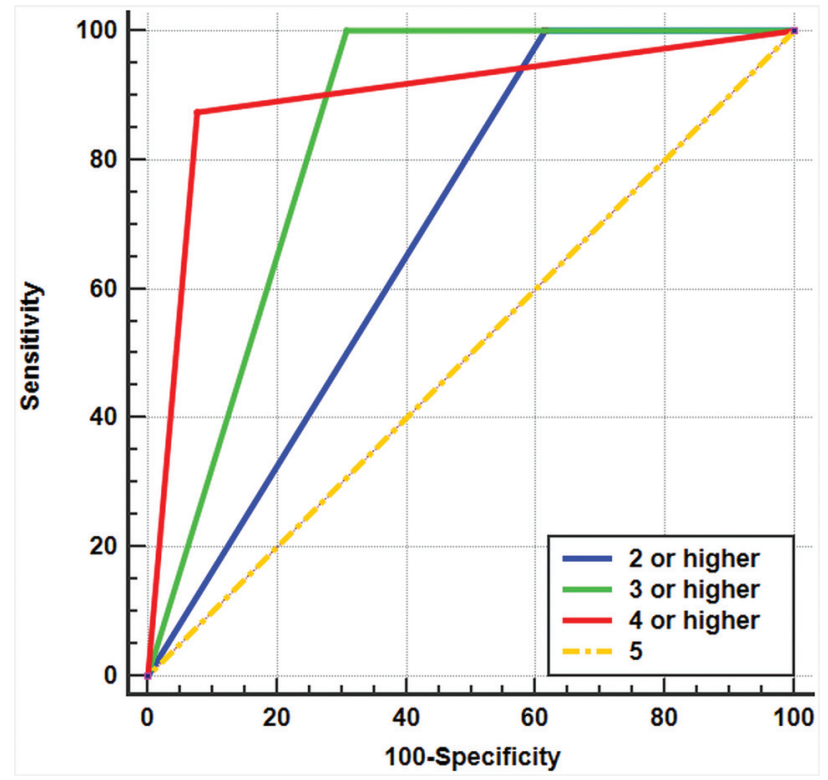

FIG 2. ROC curves for diagnosing an insecure surgical margin according to MR imaging scores for the pharyngeal constrictor muscle involvement. The ROC curve of the MR imaging score of $\geq 4$ (red) has the highest AUC value of 0.899 , followed by the MR imaging score of $\geq 3$ (green, AUC value of 0.846 ), MR imaging score of $\geq 2$ (blue, AUC value of 0.692 ), and MR imaging score of 5 (orange, AUC value of 0.500).

Table 2: Diagnostic performance of the MR imaging score for predicting an insecure surgical margin

\begin{tabular}{lccc}
\hline Cutoff Value & AUC (95\% Cl) & Sensitivity (\%) (95\% Cl) & Specificity (\%) (95\% CI) \\
\hline$\geq 2$ & $0.692(0.494-0.849)$ & $100.0(79.4-100.0)$ & $38.5(13.9-68.4)$ \\
$\geq 3$ & $0.846(0.664-0.952)$ & $100.0(79.4-100.0)$ & $69.2(38.6-90.9)$ \\
$\geq 4$ & $0.899(0.730-0.979)$ & $87.5(61.7-98.4)$ & $92.3(64.0-99.8)$ \\
5 & $0.500(0.310-0.690)$ & $0.0(0.0-24.7)$ & $100.0(79.4-100.0)$ \\
\hline
\end{tabular}

motive for future prospective clinical trials to verify the interrelation between the MR imaging score and clinical staging.

Third, during the follow-up period, 4 patients with early cancer (On-line Table 3) had locoregional recurrence. Despite the low clinical and pathologic staging, the initial MR imaging score for the pharyngeal constrictor of these patients was $\geq 3$, and the final surgical margin was close. We speculate that the preoperative MR imaging score could be associated with locoregional recurrence. However, the number of patients with locoregional recurrence was small, and the follow-up duration was rather short. Future prospective studies that can determine the statistical significance of the relationship between disease-free survival and the MR imaging score are warranted.

Our study had some limitations. First, most of the study subjects were retrospectively analyzed and thus inherently had low pre-TORS clinical and pathologic T-categories of c/pT1 and $\mathrm{c} / \mathrm{pT} 2$. In addition, the treatment-related factors such as the presence or absence of the types of adjuvant treatment were variable among the patients. However, despite the heterogeneity of the clinical data, we performed the univariable and multivariable logistic regression analyses with Firth correction to overcome this limitation, and they revealed that the MR imaging score for pharyngeal constrictor muscle invasion was a significant predictor of a surgical margin, even after the consideration of the $\mathrm{cT}$ and $\mathrm{pT}$ categories. Second, the sample size was small, and the mean follow-up period of 28.9 months was too short to firmly establish the role of MR imaging scores in predicting locoregional recurrence. Future prospective studies are warranted on a larger scale, such as a multicenter study, which can determine the relationship between the preoperative MR imaging score and clinical outcome. Third, although parapharyngeal tumor extension is a relative contraindication for TORS, ${ }^{5}$ we

Table 3: Univariable analysis of predictors of an insecure surgical margin

\begin{tabular}{|c|c|c|c|c|}
\hline Factors & Contrast & OR & $95 \% \mathrm{Cl}$ & $P$ Value \\
\hline \multirow{2}{*}{ cT category } & $\mathrm{cT} 1$ vs cT2 & 4.58 & $0.701-51.21$ & .115 \\
\hline & cTl vs cT4 & 9.0 & $0.303-1669.30$ & .208 \\
\hline $\mathrm{cN}$ category & cNO vs cN1 & 2.25 & $0.262-27.08$ & .56 \\
\hline \multirow[t]{2}{*}{ pT category } & pT1 vs pT2 & 3.49 & $0.666-23.32$ & .141 \\
\hline & pT1 vs pT4 & 6.6 & $0.255-1118.92$ & .259 \\
\hline \multirow[t]{3}{*}{$\mathrm{pN}$ category } & pNO vs $\mathrm{pNx}$ & 1.0 & $0.034-29.19$ & 1.0 \\
\hline & pNO vs pN1 & 1.09 & $0.079-14.88$ & .946 \\
\hline & pNO vs pN2 & 5.0 & $0.148-965.12$ & .378 \\
\hline \multirow[t]{2}{*}{ Histopathologic differentiation } & Well vs moderate & 0.13 & $0.001-2.00$ & .153 \\
\hline & Well vs poor & 0.36 & $0.002-7.44$ & .533 \\
\hline LVI & Positive vs negative & 1.31 & $0.296-6.094$ & .724 \\
\hline Perineural invasion & Positive vs negative & 2.61 & $0.128-394.57$ & .543 \\
\hline \multirow[t]{2}{*}{ Treatment technique } & TORS only vs TORS + adjuvant radiation & 0.78 & $0.124-4.61$ & .78 \\
\hline & TORS only vs TORS + adjuvant chemoradiation & 2.14 & $0.415-12.46$ & .366 \\
\hline \multirow[t]{4}{*}{ MR imaging score } & 1 vs $2-5$ & 21.35 & $2.03-2930.98$ & $.007^{\mathrm{a}}$ \\
\hline & $1-2$ vs $3-5$ & 69.67 & $6.68-9652.57$ & $<.0001^{\mathrm{a}}$ \\
\hline & $1-3$ vs $4-5$ & 48.33 & $7.131-634.53$ & $<.0001^{\mathrm{a}}$ \\
\hline & $1-4$ vs 5 & 3.99 & $0.653-43.33$ & .14 \\
\hline
\end{tabular}

${ }^{\mathrm{a}} P$ values $<.05$. 
Table 4: Multivariable analysis of predictors of an insecure surgical margin

\begin{tabular}{lcccc}
\hline \multicolumn{1}{c}{ Factors } & Contrast & OR & \multicolumn{1}{c}{ 95\% Cl } & P Values \\
\hline CT category & cT1 vs cT2 & 3.35 & $0.177-1013.92$ & 1.0 \\
PT category & PT1 vs pT2 & 0.60 & $0.012-9.453$ & 1.0 \\
MR imaging score & $1-3$ vs 4-5 & 6.59 & $3.11-22.28$ & $<.001^{\mathrm{a}}$ \\
\hline
\end{tabular}

${ }^{\text {a }} P$ value $<.05$.

included 6 patients who had MR imaging scores of 5 but received TORS as a first-line treatment. However, the tumor protrusion on MR imaging was not substantial in these patients; thus, we believed that parapharyngeal tumor excision could be performed as reported in a previous article. ${ }^{31}$

Fourth, there were false-negative and false-positive cases of histologic pharyngeal constrictor muscle invasion when determined by the MR imaging scores of 4 and 5 . There was also 1 patient with an MR imaging score of 5 , but with a negative surgical margin. We assumed that the reason for the false-negative cases was the microscopic tumor invasion, which could not be detected on MR imaging under its current resolution. In addition, the false-positive cases were probably due to the pushing margin, which means the tumor compressed and pushed the constrictor muscle toward the parapharyngeal fat but preserved the lateral fascia of the superior pharyngeal constrictor muscle near the pterygomandibular raphe. Future advancement in the MR imaging resolution may assist in reducing the false-negative and false-positive cases. Lastly, TORS was performed by 2 surgeons who might have had varied surgical techniques. However, both were highly experienced and equally skilled surgeons. Therefore, we can ensure that the difference in the surgical technique between the 2 surgeons had little influence on the result of the surgical margin.

\section{CONCLUSIONS}

The MR imaging-based scoring system is an effective tool for assessing pharyngeal constrictor muscle involvement in HPVpositive tonsillar SCC. An MR imaging score of $\geq 4$ was the single most significant predictive factor of an insecure surgical margin after TORS, independent of the clinical and pathologic staging. Therefore, the preoperative MR imaging scoring system for the pharyngeal constrictor muscle is a promising predictor of the final surgical margin, thereby assisting in the appropriate selection of TORS treatment of HPV-positive tonsillar SCC, even in early T2 tumors.

\section{ACKNOWLEDGMENTS}

We thank the Medical Research Collaborating Center at Seoul National University Bundang Hospital for assisting with statistical analyses and Editage (www.editage.co.kr) for English language editing.

\section{REFERENCES}

1. Chaturvedi AK, Engels EA, Pfeiffer RM, et al. Human papillomavirus and rising oropharyngeal cancer incidence in the United States. J Clin Oncol 2011;29:4294-301 CrossRef Medline
2. Morisod B, Venara V, II, Alzuphar S, et al. Minimizing adjuvant treatment after transoral robotic surgery through surgical margin revision and exclusion of radiographic extracapsular extension: a prospective observational cohort study. Head Neck 2017;39:965-73 CrossRef Medline

3. Persky MJ, Albergotti WG, Rath TJ, et al. Positive margins by oropharyngeal subsite in transoral robotic surgery for T1/T2 squamous cell carcinoma. Otolaryngol Head Neck Surg 2018;158:660-66 CrossRef Medline

4. Ang KK, Sturgis EM. Human papillomavirus as a marker of the natural history and response to therapy of head and neck squamous cell carcinoma. Semin Radiat Oncol 2012;22:128-42 CrossRef Medline

5. Baskin RM, Boyce BJ, Amdur R, et al. Transoral robotic surgery for oropharyngeal cancer: patient selection and special considerations. Cancer Manag Res 2018;10:839-46 CrossRef Medline

6. Park YM, Jung CM, Cha D, et al. A new clinical trial of neoadjuvant chemotherapy combined with transoral robotic surgery and customized adjuvant therapy for patients with $\mathrm{T} 3$ or T4 oropharyngeal cancer. Ann Surg Oncol 2017;24:3424-29 CrossRef Medline

7. Mirghani H, Blanchard P. Treatment de-escalation for HPV-driven oropharyngeal cancer: where do we stand? Clin Transl Radiat Oncol 2018;8:4-11 CrossRef Medline

8. Masterson L, Moualed D, Liu ZW, et al. De-escalation treatment protocols for humanpapillomavirus-associated oropharyngeal squamous cell carcinoma: a systematic review and meta-analysis of current clinical trials. Eur J Cancer 2014;50:2636-48 CrossRef Medline

9. Chen AM, Felix C, Wang PC, et al. Reduced-dose radiotherapy for humanpapillomavirus-associated squamous-cell carcinoma of the oropharynx: a single-arm, Phase 2 study. Lancet Oncol 2017;18:80311 CrossRef Medline

10. Mallen-St Clair J, Alani M, Wang MB, et al. Human papillomavirus in oropharyngeal cancer: the changing face of a disease. Biochim Biophys Acta 2016;1866:141-50 CrossRef Medline

11. Eisbruch A, Schwartz M, Rasch C, et al. Dysphagia and aspiration after chemoradiotherapy for head-and-neck cancer: which anatomic structures are affected and can they be spared by IMRT? Int J Radiat Oncol Biol Phys 2004;60:1425-39 CrossRef Medline

12. Rieger JM, Zalmanowitz JG, Wolfaardt JF. Functional outcomes after organ preservation treatment in head and neck cancer: a critical review of the literature. Int J Oral Maxillofac Surg 2006;35:58187 CrossRef Medline

13. Machtay M, Moughan J, Trotti A, et al. Factors associated with severe late toxicity after concurrent chemoradiation for locally advanced head and neck cancer: an RTOG analysis. J Clin Oncol 2008;26:358289 CrossRef Medline

14. Bhayani MK, Holsinger FC, Lai SY. A shifting paradigm for patients with head and neck cancer: transoral robotic surgery (TORS). Oncology (Williston Park) 2010;24:1010-15 Medline

15. Mydlarz WK, Chan JY, Richmon JD. The role of surgery for HPV-associated head and neck cancer. Oral Oncol 2015;51:305-13 CrossRef Medline

16. Duek I, Billan S, Amit M, et al. Transoral robotic surgery in the HPV era. Rambam Maimonides Med J 2014;5:e0010 CrossRef Medline

17. Holsinger FC, McWhorter AJ, Ménard M, et al. Transoral lateral oropharyngectomy for squamous cell carcinoma of the tonsillar region, I: technique, complications, and functional results. Arch Otolaryngol Head Neck Surg 2005;131:583-91 CrossRef Medline

18. Moore EJ, Janus J, Kasperbauer J. Transoral robotic surgery of the oropharynx: clinical and anatomic considerations. Clin Anat 2012;25:135-41 CrossRef Medline

19. Chen MM, Roman SA, Kraus DH, et al. Transoral robotic surgery: a population-level analysis. Otolaryngol Head Neck Surg 2014;150:96875 CrossRef Medline

20. An Y, Park HS, Kelly JR, et al. The prognostic value of extranodal extension in human papillomavirus-associated oropharyngeal squamous cell carcinoma. Cancer 2017;123:2762-72 CrossRef Medline

21. Zhan KY, Eskander A, Kang SY, et al. Appraisal of the AJCC 8th edition pathologic staging modifications for $\mathrm{HPV}$-positive 
oropharyngeal cancer, a study of the National Cancer Data Base. Oral Oncol 2017;73:152-59 CrossRef Medline

22. NCCN Clinical Practice Guideline Sin Oncology. 2018 Version I.2018. https://www.firsthospital.cn/upload/doc/201911/21175519.pdf. Accessed May 13, 2018

23. Fleiss J, Levin B, Paik MC. Statistical Methods for Rates and Proportions. 2nd ed. John Wiley; 1981:38-46

24. DeLong ER, DeLong DM, Clarke-Pearson DL. Comparing the areas under two or more correlated receiver operating characteristic curves: a nonparametric approach. Biometrics 1988;44:837-45 CrossRef Medline

25. Heinze G, Schemper M. A solution to the problem of monotone likelihood in Cox regression. Biometrics 2001;57:114-19 CrossRef Medline

26. Cracchiolo JR, Roman BR, Kutler DI, et al. Adoption of transoral robotic surgery compared with other surgical modalities for treatment of oropharyngeal squamous cell carcinoma. J Surg Oncol 2016;114:405-11 CrossRef Medline
27. Moore EJ, Van Abel KM, Price DL, et al. Transoral robotic surgery for oropharyngeal carcinoma: surgical margins and oncologic outcomes. Head Neck 2018;40:747-55 CrossRef Medline

28. Funk RK, Moore EJ, Garcia JJ, et al. Risk factors for locoregional relapse after transoral robotic surgery for human papillomavirusrelated oropharyngeal squamous cell carcinoma. Head Neck 2016;38(Suppl 1):E1674-79 CrossRef Medline

29. Cracchiolo JR, Baxi SS, Morris LG, et al. Increase in primary surgical treatment of $\mathrm{T} 1$ and $\mathrm{T} 2$ oropharyngeal squamous cell carcinoma and rates of adverse pathologic features: National Cancer Data Base. Cancer 2016;122:1523-32 CrossRef Medline

30. Weinstein GS, O'Malley BW Jr, Rinaldo A, et al. Understanding contraindications for transoral robotic surgery (TORS) for oropharyngeal cancer. Eur Arch Otorhinolaryngol 2015;272:1551-52 CrossRef Medline

31. Chan JY, Tsang RK, Eisele DW, et al. Transoral robotic surgery of the parapharyngeal space: a case series and systematic review. Head Neck 2015;37:293-98 CrossRef Medline 


\section{ON-LINE APPENDIX : MATERIALS AND METHODS}

\section{Image Acquisition}

The noncontrast sequences were obtained in the following order: 1) coronal TSE T2WI with fat suppression using a multipoint Dixon technique (TR, $2500 \mathrm{~ms}$; TE, $80 \mathrm{~ms}$; FOV, $200 \times 200 \mathrm{~mm}^{2}$; acquisition matrix, $400 \times 400$; section thickness, $4 \mathrm{~mm}$; section gap, $0.4 \mathrm{~mm}$; NEX, 1); 2) axial TSE T2WI with and without fat suppression (TR, $3300 \mathrm{~ms}$; TE, $80 \mathrm{~ms}$; FOV, $180 \times 220 \mathrm{~mm}^{2}$; acquisition matrix, $440 \times 440$; section thickness, $3 \mathrm{~mm}$; no section gap; NEX, 1); 3) axial TSE T1WI without fat suppression (TR, $690 \mathrm{~ms}$; TE, $15 \mathrm{~ms}$; FOV, $180 \times 220 \mathrm{~mm}^{2}$; acquisition matrix, $440 \times 440$; section thickness, $3 \mathrm{~mm}$; no section gap; NEX, 1); 4) axial multishot EPIbased DWI ( 2 b-values of 0 and $1000 \mathrm{~s} / \mathrm{mm}^{2} ; 3$ orthogonal diffusion gradients; TR, $6400 \mathrm{~ms}$; TE, $65 \mathrm{~ms}$; FOV, $220 \times 220 \mathrm{~mm}^{2}$; acquisition matrix, $128 \times 128$; section thickness, $3 \mathrm{~mm}$; no section gap; number of sections, 40; number of shots, 4; NEX, 2). After intravenous administration of a bolus of gadolinium-based contrast-agent (gadobutrol, Gadovist, $0.1 \mathrm{mmol} / \mathrm{kg}$; Bayer Schering Pharma), contrast-enhanced TSE T1WI with fat-suppression images in axial (TR, $600 \mathrm{~ms}$; TE, $15 \mathrm{~ms}$; FOV, $180 \times 220 \mathrm{~mm}^{2}$; acquisition matrix, $440 \times 440$; section thickness, $3 \mathrm{~mm}$; no section gap; NEX, 1), coronal (TR, $550 \mathrm{~ms}$; TE, $15 \mathrm{~ms}$; FOV, $200 \times 200 \mathrm{~mm}^{2}$; acquisition matrix, $400 \times 400$; section thickness, $4 \mathrm{~mm}$; section gap, $0.4 \mathrm{~mm}$; NEX, 1), and sagittal (TR, $560 \mathrm{~ms}$; TE, $15 \mathrm{~ms}$; FOV, $250 \times 250 \mathrm{~mm}^{2}$; acquisition matrix, $500 \times 500$; section thickness, $4 \mathrm{~mm}$; section gap, $0.4 \mathrm{~mm}$; NEX, 1) planes were acquired.

On-line Table 1: Summary of the patient information

\begin{tabular}{|c|c|c|c|c|c|c|c|c|c|c|}
\hline No. & Age (yr) & Sex & $\mathrm{cT} / \mathrm{cN}$ & $\mathrm{pT} / \mathrm{pN}$ & $\begin{array}{c}\text { MR } \\
\text { Imaging } \\
\text { Score }\end{array}$ & $\begin{array}{l}\text { Surgical } \\
\text { Margin }\end{array}$ & LVI & $\begin{array}{l}\text { Perineural } \\
\text { Invasion }\end{array}$ & ENE & $\begin{array}{l}\text { Adjuvant } \\
\text { Treatment }\end{array}$ \\
\hline 1 & 38 & $M$ & $2 / 1$ & $1 / 1$ & 3 & Negative & Positive & Negative & Negative & CCRT \\
\hline 2 & 60 & M & $2 / 1$ & $2 / 1$ & 2 & Negative & Positive & Negative & Negative & CCRT \\
\hline 3 & 53 & $M$ & $2 / 1$ & $2 / 1$ & 2 & Negative & Negative & Negative & Present & CCRT \\
\hline 4 & 80 & $M$ & $2 / 1$ & $2 / 2$ & 3 & Positive & Negative & Negative & Present & CCRT \\
\hline 5 & 55 & M & $4 / 1$ & $4 / 1$ & 5 & Positive & Positive & Positive & Present & CCRT \\
\hline 6 & 69 & $M$ & $2 / 1$ & $2 / 1$ & 4 & Positive & Positive & Negative & Present & CCRT \\
\hline 7 & 79 & M & $2 / 1$ & $2 / 1$ & 5 & Positive & Negative & Negative & Present & CCRT \\
\hline 8 & 56 & $M$ & $2 / 1$ & $2 / 1$ & 5 & Close & Negative & Negative & Present & CCRT \\
\hline 9 & 63 & M & $2 / 1$ & $2 / 2$ & 4 & Close & Positive & Negative & Negative & CCRT \\
\hline 10 & 57 & $M$ & $2 / 1$ & $2 / 1$ & 4 & Close & Positive & Negative & Negative & CCRT \\
\hline 11 & 52 & $\mathrm{~F}$ & $2 / 1$ & $2 / 1$ & 2 & Negative & Positive & Negative & Negative & RT \\
\hline 12 & 47 & $\mathrm{~F}$ & $1 / 1$ & $1 / 2$ & 1 & Negative & Negative & Negative & Negative & RT \\
\hline 13 & 54 & M & $2 / 1$ & $2 / 1$ & 5 & Negative & Negative & Negative & Negative & RT \\
\hline 14 & 76 & $\mathrm{~F}$ & $2 / 1$ & $2 / 1$ & 3 & Negative & Positive & Negative & Negative & RT \\
\hline 15 & 63 & M & $2 / 1$ & $2 / x$ & 5 & Close & Negative & Negative & NA & RT \\
\hline 16 & 56 & M & $2 / 1$ & $1 / 1$ & 3 & Close & Negative & Positive & Negative & RT \\
\hline 17 & 68 & M & $2 / 1$ & $2 / 1$ & 5 & Close & Positive & Negative & Negative & RT \\
\hline 18 & 52 & M & $1 / 1$ & $1 / 1$ & 4 & Close & Positive & Negative & Present & RT \\
\hline 19 & 78 & $M$ & $2 / 1$ & $2 / 1$ & 1 & Negative & Positive & Negative & Negative & None \\
\hline 20 & 76 & M & $1 / 0$ & $1 / x$ & 1 & Negative & Negative & Negative & NA & None \\
\hline 21 & 63 & M & $2 / 1$ & $2 / 1$ & 1 & Negative & Negative & Negative & Negative & None \\
\hline 22 & 67 & $M$ & $1 / 1$ & $1 / 1$ & 3 & Negative & Negative & Negative & Negative & None \\
\hline 23 & 59 & M & $1 / 1$ & $1 / 1$ & 1 & Negative & Negative & Negative & Negative & None \\
\hline 24 & 54 & M & $2 / 0$ & $2 / 0$ & 2 & Negative & Negative & Negative & Negative & None \\
\hline 25 & 75 & M & $2 / 1$ & $2 / 1$ & 4 & Positive & Positive & Negative & Negative & None \\
\hline 26 & 45 & M & $2 / 1$ & $2 / 1$ & 4 & Positive & Negative & Negative & Negative & None \\
\hline 27 & 54 & M & $2 / 1$ & $2 / 1$ & 4 & Positive & Negative & Negative & Negative & None \\
\hline 28 & 70 & $M$ & $2 / 0$ & $2 / 0$ & 4 & Close & Negative & Negative & Negative & None \\
\hline 29 & 68 & $M$ & $2 / 1$ & $2 / 1$ & 4 & Close & Positive & Negative & Present & None \\
\hline
\end{tabular}

Note-ENE indicates extranodal extension; CCRT, chemoradiation; RT, radiation; NA, not applicable; LVI, lymphovascular invasion.

On-line Table 2: Preoperative MR imaging scores and histologic pharyngeal constrictor muscle invasion

\begin{tabular}{|c|c|c|c|c|c|c|c|}
\hline & & 1 & 2 & 3 & 4 & 5 & $P$ Value \\
\hline \multirow[t]{2}{*}{ Histologic pharyngeal constrictor muscle invasion } & Negative & 5 & 2 & 4 & 4 & 0 & \multirow[t]{2}{*}{$.002^{\mathrm{a}}$} \\
\hline & Positive & 0 & 2 & 1 & 5 & 6 & \\
\hline
\end{tabular}

\footnotetext{
${ }^{\mathrm{a}} \mathrm{P}$ value $<.05$
} 


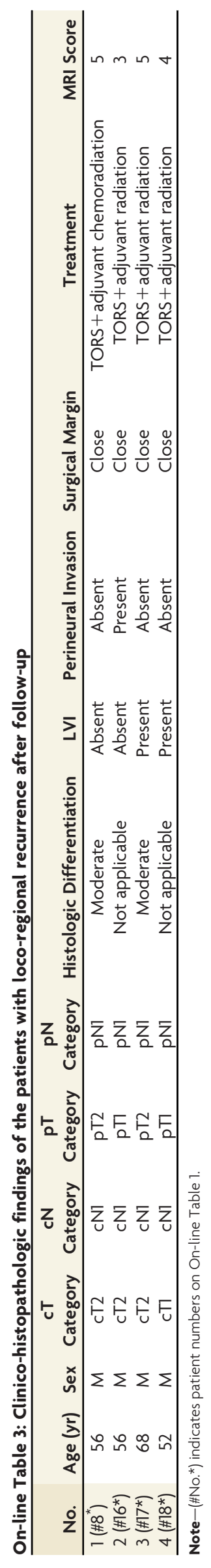



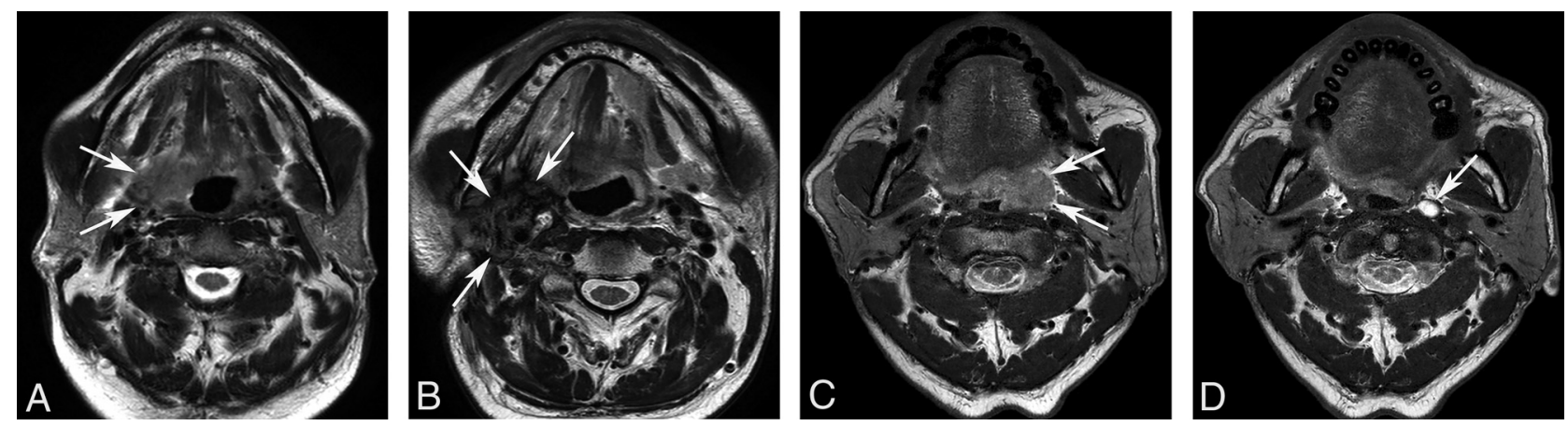

ON-LINE FIGURE. Representative cases of locoregional recurrence, A, A 67-year-old man with right-tonsillar SCC (arrows) shows an MR imaging score of 5 for pharyngeal constrictor muscle involvement on the initial axial T2WI. B. On his 6-month follow-up MR imaging, a large recurrent tumor (arrows) has developed in the right TORS site. C, Pre-TORS axial T2WI of another 68-year-old man who was diagnosed with left-tonsillar SCC shows tumor protrusion into the parapharyngeal fat (arrows) (MR imaging score of 5). D. At 3 months after TORS, new left retropharyngeal lymph node metastasis (arrow) has developed. 